\title{
Bioremediasi Lumpur Alum menggunakan Aspergillus niger dengan Penambahan Serbuk Gergaji sebagai Bulking Agent
}

\author{
Indira Wido Primadipta dan Harmin Sulistiyaning Titah \\ Jurusan Teknik Lingkungan, Fakultas Teknik Sipil dan Perencanaan, Institut Teknologi Sepuluh \\ Nopember (ITS) \\ Jl. Arief Rahman Hakim, Surabaya 60111 Indonesia \\ e-mail: harmin_st@its.ac.id
}

\begin{abstract}
Abstrak-Penggunaan koagulan $\mathrm{Al}_{2} \mathrm{SO}_{4}$ dalam pengolahan air minum dan menghasilkan produk samping berupa lumpur alum. Dampak yang ditimbulkan dari akumulasi aluminium di badan sungai yakni dapat membahayakan kesehatan manusia dan mengganggu kelangsungan hidup biota sungai. Bioremediasi merupakan salah satu teknologi remediasi yang memanfaatkan mikroorganismen dan dapat digunakan untuk menyisihkan logam aluminium. Salah satu mikroorganisme yang dapat menyisihkan logam aluminium adalah jamur Aspergillus niger. Tujuan penelitian ini adalah untuk menentukan karakteristik awal lumpur alum dari IPAM X meliputi konsentrasi aluminium, pH, suhu, densitas, kadar air serta porositas, efisiensi penyisihan aluminium dengan variasi penambahan serbuk gergaji sebagai bulking agent dan konsentrasi penambahan jamur Aspergillus niger (5 dan $10 \%(\mathrm{v} / \mathrm{v})$ ) serta bioremediasi paling efektif berdasarkan berbagai variasi yang telah disebutkan. Karakteristik lumpur alum dari IPAM X yakni memiliki konsentrasi aluminium $250 \mathrm{mg} / \mathrm{L}$, pH 8,61 dengan suhu $31^{\circ} \mathrm{C}$, massa jenis $1240 \mathrm{~kg} / \mathrm{m}^{3}$, kadar air $98 \%$ serta angka porositasnya 0,0230. Pada penambahan 5 dan $10 \%$ (v/v) Aspergillus niger didapatkan efisiensi penyisihan aluminium pada sampel $100 \%$ lumpur alum yakni masing-masing $8,45 \%$ dan $9,08 \%$ sedangkan pada sampel $97 \%$ lumpur alum dan $3 \%$ serbuk gergaji yakni masing-masing $8,27 \%$ dan $10,11 \%$. Didapatkan kesimpulan bahwa bioremediasi yang paling efektif untuk penyisihan aluminium yakni pada penambahan $10 \%$ (v/v) Aspergillus niger pada $97 \%$ lumpur alum dan $3 \%$ serbuk gergaji sebesar $10,11 \%$.
\end{abstract}

Kata Kunci-Aspergillus niger, bioremediasi, aluminium, lumpur alum

\section{PENDAHULUAN}

$\mathrm{K}^{\mathrm{o}}$ OAGULAN aluminium sulfat $\left(\mathrm{Al}_{2} \mathrm{SO}_{4}\right)$ digunakan dalam proses pengolahan air minum dan menghasilkan produk samping berupa lumpur alum [1]. Lumpur alum pada unit accelator pada IPAM X dibuang secara langsung ke badan sungai tanpa pengolahan lebih lanjut [2]. Aluminium yang berasal dari lumpur alum tanpa melewati pengolahan lumpur adalah sebesar 27-153 (g/kg) [3]. Rujukan lain menyatakan bahwa kadar aluminium total pada unit accelator adalah sebesar 4794 (mg/L) [4]. Limbah lumpur yang berasal dari pengolahan air bersih PDAM memiliki kandungan logam aluminium yang tergolong sebagai limbah Bahan Berbahaya dan Beracun (B3) [5]. Toksisitas aluminium pada manusia dapat menyebabkan kerusakan jaringan detoksifikasi, serta ekskresi hati dan ginjal [5]. Apabila lumpur alum dibuang ke badan sungai maka dapat menyebabkan terjadinya pendangkalan sungai. Dampak lain yang ditimbulkan adalah membahayakan kesehatan manusia yang menggunakan air sungai, serta kelangsungan hidup biota sungai akan terganggu akibat akumulasi lumpur alum yang berada di badan sungai [6][7]. Klasifikasi standar kandungan aluminium dalam $\mathrm{pH}$ 6,5 untuk kualitas air permukaan, yakni pada kelas 5 memiliki konsentrasi aluminium yang ada di dalam permukaan air mencapai kondisi toksik bagi perairan, yakni $>75 \mu \mathrm{g} / \mathrm{L}$ [8].

Bioremediasi merupakan salah satu teknologi remediasi yang memanfaatkan mikroorganisme. Teknologi ini digunakan untuk remediasi sebuah area dan dapat memperbaiki sebuah lahan yang tercemar secara menyeluruh [9]. Teknologi bioremediasi dipilih karena ekonomis, cukup efektif, efisien, dan lebih ramah lingkungan [10]. Beberapa mikroorganisme yang dapat digunakan untuk bioremediasi logam adalah Bacillus spp., Pseudomonas spp., Staphylococcus spp., dan Aspergillus niger [11]. Aspergillus niger resisten dengan kadar aluminium sebesar $2000 \mathrm{mg} / \mathrm{L}$ [12]. Aspergillus niger mampu untuk menurunkan konsentrasi aluminium pada iron slime sebanyak $38,1 \%$ [13].

Laju biodegradasi dalam proses bioremediasi dapat ditingkatkan dengan penambahan bulking agent. Bulking agent adalah bahan tambahan yang digunakan untuk memperbaiki permeabilitas dan meningkatkan laju biodegradasi dalam proses pemulihan. Bulking agent juga berfungsi sebagai pengatur porositas, kelembaban, dan sumber nutrisi. Bulking agents yang digunakan berupa serbuk gergaji, sludge sisa biogas, dan kompos [14]. Bioremediasi dengan penambahan serbuk gergaji halus sebanyak 500 gram menghasilkan penurunan TPH hingga $44 \%$ dibandingkan dengan bioremediasi tanpa menggunakan serbuk gergaji ataupun bulking agent lainnya yakni hanya menghasilkan penurunan TPH sebesar 20\% [15].

Berdasarkan latar belakang diatas, maka tujuan dari penelitian ini adalah untuk menentukan karakteristik awal lumpur alum dari IPAM X meliputi konsentrasi aluminium, $\mathrm{pH}$, suhu, densitas, kadar air serta porositas, efisiensi penyisihan aluminium dengan variasi penambahan serbuk gergaji sebagai bulking agent dan konsentrasi penambahan jamur Aspergillus niger (5 dan $10 \%(\mathrm{v} / \mathrm{v})$ ) serta bioremediasi paling efektif berdasarkan berbagai variasi yang telah disebutkan. 


\section{METODE PENELITIAN}

\section{A. Pengambilan Sampel Lumpur Alum}

Pengambilan sampel pada penelitian ini menggunakan sampel sesaat (grab sample). Sampel sesaat merupakan sampel yang mewakili keadaan lumpur pada suatu tempat. Apabila lumpur mempunyai karakteristik tidak banyak berubah di dalam satu periode atau di dalam batas jarak waktu tertentu, maka contoh sesaat tersebut cukup mewakili keadaan waktu dan tempat tersebut. Prosedur pengambilan sampel pada penelitian ini meliputi pewadahan sampel, selang waktu antara sampling dan analisa, dan pengawetan sampel jika diperlukan [16].

\section{B. Uji Karakterisasi Lumpur Alum}

Uji karakterisasi lumpur alum menggunakan metode pengujian yakni destruksi basah. Lumpur alum dianalisis kadar air, $\mathrm{pH}$, suhu dan massa jenisnya. Pengukuran kadar air berdasarkan metode gravimetri yakni selisih berat cawan awal dan akhir (setelah dimasukkan ke dalam oven $105^{\circ} \mathrm{C}$ ) dengan rumus empiris yakni [17]:

$$
\text { Kadar air }(\%)=\frac{(a-b)}{a}
$$

Keterangan:

$a$ = massa sampel awal

$b \quad$ = massa sampel setelah dikeringkan

Sedangkan perhitungan massa jenis lumpur alum dengan rumus empiris sebagai berikut [18]:

$$
\rho=\frac{m}{v}
$$

Keterangan:

$\rho \quad=$ massa jenis sampel $\left(\mathrm{kg} / \mathrm{m}^{3}\right)$

$m$ = massa sampel $(\mathrm{kg})$

$v \quad=$ volume sampel $\left(\mathrm{m}^{3}\right)$

\section{Uji Porositas Sampel}

Uji porositas sampel digunakan untuk mengetahui angka pori dari masing-masing sampel, kemudian dipilih satu sampel dengan angka pori tertinggi yang akan digunakan sebagai variabel dalam penelitian. Faktor porositas berpengaruh dalam proses mikroorganisme melakukan penurunan konsentrasi logam aluminium di dalam sampel. Uji porositas menggunakan metode volumetri dan gravimetri untuk menentukan angka pori dari masing-masing sampel uji yakni 99\% lumpur alum: 1\% serbuk gergaji, $98 \%$ lumpur alum: $2 \%$ serbuk gergaji dan $97 \%$ lumpur alum: 3\% serbuk gergaji.

\section{Uji Parameter}

Parameter yang diuji dalam penelitian ini dilakukan sebanyak 24 jam sekali untuk $\mathrm{pH}$, kadar air dan suhu. Pengukuran konsentrasi aluminium diukur 2 kali yakni pada awal dan akhir penelitian sedangkan pengukuran jumlah koloni bakteri dan jamur dilakukan 3 kali yakni pada hari pertama, ketiga dan kelima penelitian. Parameter yang digunakan dalam penelitian ini adalah pengukuran $\mathrm{pH}$ dengan $\mathrm{pHmeter}$ (Cyberscan 510, USA), suhu dilakukan dengan menggunakan termometer (EC
10 PhonLab, USA), kadar air dilakukan dengan mengambil sampel lumpur sebanyak 10 gram ditempatkan dalam cawan porselen. Kadar air dihitung dengan metode gravimetri dan menggunakan rumus (1), konsentrasi total aluminium dengan metode destruksi basah yang selanjutnya dianalisis dengan Atomic Absorption Spectrometry (AAS) (Reyleigh WFX 210, Beijing) serta pengukuran jumlah koloni bakteri dan jamur menggunakan metode $\mathrm{CFU}$.

\section{E. Uji Penyisihan Logam Aluminium}

Pada penelitian ini variasi komposisi dari lumpur alum dan serbuk gergaji disesuaikan dengan hasil uji porositas. Total sampel yang akan digunakan adalah $500 \mathrm{ml}$ karena disesuaikan dengan kebutuhan dan reaktor yang digunakan. Sedangkan mikroorganisme yang digunakan yakni jamur Aspergillus niger. Konsentrasi jamur yang dipakai adalah 5\% (v/v) dan $10 \%$ (v/v). Tahap inokulasi jamur adalah menggunakan koloni jamur yang telah diinkubasi selama 3 hari pada beberapa media PDA miring. Koloni jamur pada media agar miring ditambahkan $5 \mathrm{ml}$ larutan salin kemudian koloni digores perlahan dengan jarum ose hingga seluruh koloni terlepas dari media PDA miring, selanjutnya larutan salin dan koloni jamur Aspergillus niger dihomogenkan dan diukur absorbansinya hingga mencapai $\mathrm{OD}_{405}=1$ [19]. Uji penyisihan logam aluminium dilakukan selama 5 hari di dalam reaktor kaca berukuran $650 \mathrm{ml}$ sebanyak 6 reaktor secara duplo dengan keterangan pada Tabel 1.

Tabel 1.

Kode Reaktor

\begin{tabular}{cc}
\multicolumn{2}{c}{ Kode Reaktor } \\
\hline No & Kode Reaktor \\
\hline $\mathbf{1}$ & Kontrol 1 \\
$\mathbf{2}$ & J5LA \\
$\mathbf{3}$ & J0LA \\
$\mathbf{4}$ & Kontrol 2 \\
$\mathbf{5}$ & J5SG \\
$\mathbf{6}$ & J0SG \\
\hline
\end{tabular}

Keterangan Tabel 1:

Kontrol 1 = Kontrol 100\% Lumpur Alum tanpa

Penambahan Jamur A. niger

Kontrol 2 = Kontrol 97\% Lumpur Alum: 3\%

Serbuk Gergaji tanpa Penambahan

Jamur A. niger

$\mathrm{J}=$ = Penambahan Jamur A. niger

$5=$ Penambahan $5 \% \mathrm{v} / \mathrm{v}$ Jamur $A$. niger

$0 \quad=$ Penambahan $10 \% \mathrm{v} / \mathrm{v}$ Jamur $A$. niger

LA $\quad=100 \%$ Lumpur Alum

SG $\quad=97 \%$ Lumpur Alum: $3 \%$ Serbuk Gergaji

\section{HASIL DAN PEMBAHASAN}

\section{A. Analisis Karakteristik Lumpur Alum}

Uji karakteristik lumpur alum meliputi konsentrasi aluminium, $\mathrm{pH}$, suhu, massa jenis dan kadar air. Penelitian pendahuluan ini bertujuan untuk mengetahui karakteristik aluminium awal yang akan dipakai sebagai sampel dalam 
penelitian ini. Berdasarkan rumus (1), maka massa jenis lumpur alum $1240 \mathrm{~kg} / \mathrm{m}^{3}$. Pengukuran kadar air menggunakan metode gravimetri sehingga diperoleh kadar air lumpur alum sebesar 98\%. Pengukuran $\mathrm{pH}$ dan suhu sampel lumpur alum secara berturut-turut yakni 8,61 dan $31^{\circ} \mathrm{C}$. Konsentrasi aluminium pada lumpur alum yakni $250 \mathrm{mg} / \mathrm{L}$ dengan menggunakan metode destruksi basah dan pengukuran melalui AAS.

\section{B. Analisis Porositas Sampel}

Sampel yang memiliki angka pori paling tinggi akan digunakan sebagai sampel dalam penelitian. Uji porositas yakni menggunakan 3 jenis sampel yang dibedakan berdasarkan rasio pencampuran antara lumpur alum dan serbuk gergaji. Pada penambahan serbuk gergaji diatas $3 \%$, sampel menjadi tidak proporsional yakni komposisi serbuk gergaji yang lebih dominan dibandingkan dengan lumpur alum dalam sampel.

Tabel 2.

Porositas Sampel

\begin{tabular}{clc}
\hline No & \multicolumn{1}{c}{ Rasio Sampel } & $\begin{array}{c}\text { Angka } \\
\text { Porositas }\end{array}$ \\
\hline $\mathbf{1}$ & 100\% Lumpur Alum & 0,0230 \\
$\mathbf{2}$ & 1\% Serbuk Gergaji : 99\% Lumpur Alum & 0,0540 \\
$\mathbf{3}$ & 2\% Serbuk Gergaji : 98\% Lumpur Alum & 0,0555 \\
$\mathbf{4}$ & 3\% Serbuk Gergaji : 97\% Lumpur Alum & 0,0579 \\
\hline
\end{tabular}

Berdasarkan Tabel 2 dapat diperoleh angka porositas terbesar yakni pada komposisi sampel dengan rasio 3\% serbuk gergaji: $97 \%$ lumpur alum sebesar 0,0579 yang selanjutnya digunakan sebagai salah satu sampel penelitian.

\section{Analisis Total Koloni Jamur}

Analisis total koloni jamur digunakan untuk mengetahui jumlah jamur yang ada di dalam sampel uji. Jumlah koloni jamur diencerkan hingga $10^{2}, 10^{3}$, dan $10^{4}$. Pengenceran bertujuan agar jumlah koloni jamur yang terbentuk berada pada rentang 15-150 koloni. Proses inkubasi jamur dilakukan selama 2 hari (sebelum kemunculan hifa) agar mempermudah penghitungan. Adapun hasil pengamatan disajikan dalam bentuk grafik pada Gambar 1 untuk penambahan 5\% (v/v) dan pada Gambar 2 untuk penambahan 10\% (v/v) jamur.

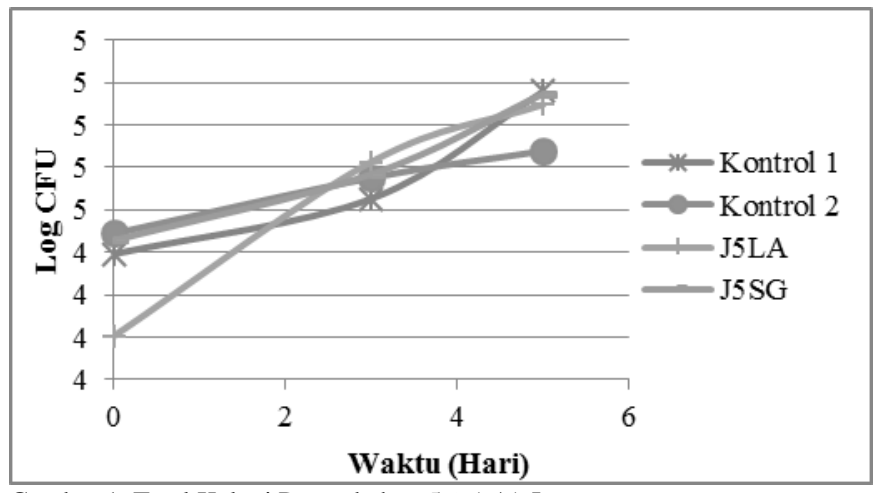

Gambar 1. Total Koloni Penambahan 5\% (v/v) Jamur

Pada Gambar 1 diketahui bahwa pertumbuhan kontrol yakni kontrol 1 dan 2 terdapat jamur indigenous yang terdapat pada lumpur alum maupun serbuk gergaji. Hal ini dikarenakan pada awal penelitian lumpur alum dan serbuk gergaji tidak disterilkan. Hal ini dilakukan agar sampel tersebut dapat menjadi kontrol dalam pengaruh penambahan bakteri dan jamur (augmentasi) terhadap kadar penyisihan aluminium.

Selanjutnya pada reaktor J5LA dan J5SG terjadi kenaikan jumlah koloni jamur selama pengukuran pada awal, tengah dan akhir penelitian. Hal tersebut dapat disimpulkan bahwa jamur mampu beradaptasi dari awal waktu inokulasi ke dalam sampel uji.

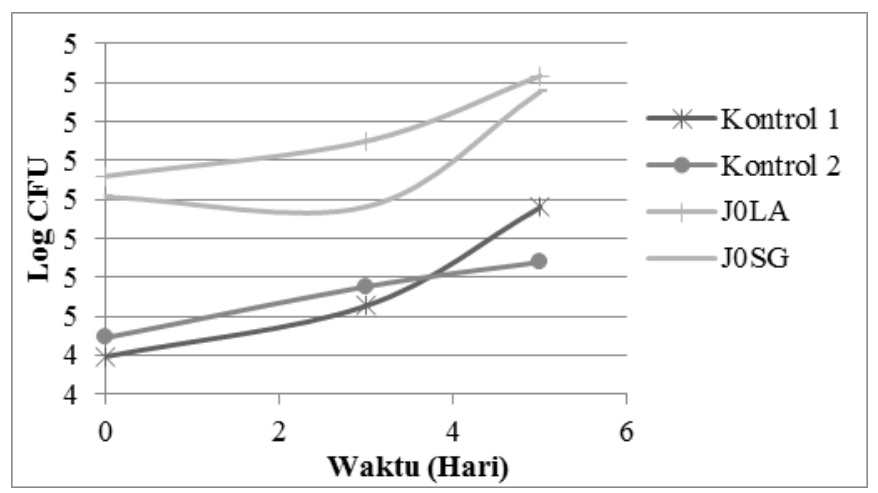

Gambar 2. Total Koloni Penambahan 10\% (v/v) Jamur

Selanjutnya, pada Gambar 2 menunjukkan bahwa pada reaktor JOLA mengalami kenaikan dari awal hingga akhir pengukuran total koloni. Hal ini mengindikasikan bahwa jamur mampu beradaptasi dengan cepat dari awal hingga akhir penelitian. Kemudian pada reaktor J0SG menunjukkan penurunan pada hari ketiga pengukuran dan mengalami kenaikan kembali pada pengukuran hari kelima. Hal ini menunjukkan bahwa jamur masih dalam proses beradaptasi terhadap sampel uji.

\section{Analisis Suhu}

Pengukuran suhu dilakukan setiap 24 jam sekali dalam 5 hari waktu penelitian. Suhu dalam setiap reaktor bervariasi dan dapat dilihat pada Gambar 2.

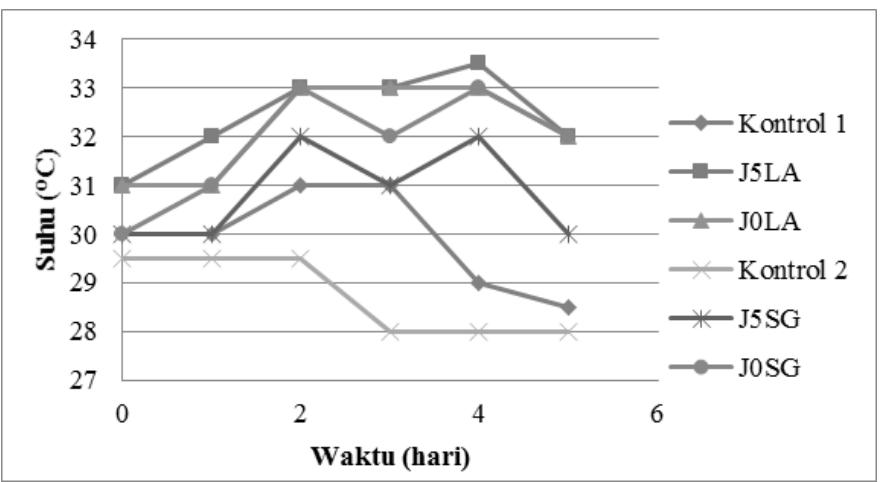

Gambar 3. Suhu Uji Penyisihan Logam Aluminium

Pada Gambar 3 menunjukkan suhu pada reaktor yang ditambahkan jamur A. niger. Rentang suhu pada saat uji penyisihan logam aluminium yakni pada rentang suhu 28$33,5^{\circ} \mathrm{C}$. Hal ini menunjukkan bahwa rentang nilai suhu saat pengukuran masih termasuk di dalam rentang suhu pertumbuhan jamur A. niger. A. niger hidup pada suhu $20^{\circ}-$ $40^{\circ} \mathrm{C}$ dengan suhu optimal $37^{\circ} \mathrm{C}$ [20]. 


\section{E. Analisis $p H$}

Parameter lain yang diukur selama pelaksaan penelitian adalah $\mathrm{pH}$. Pada kondisi $\mathrm{pH}$ optimal maka proses bioremediasi logam yang dilakukan oleh Aspergillus niger akan semakin optimal.

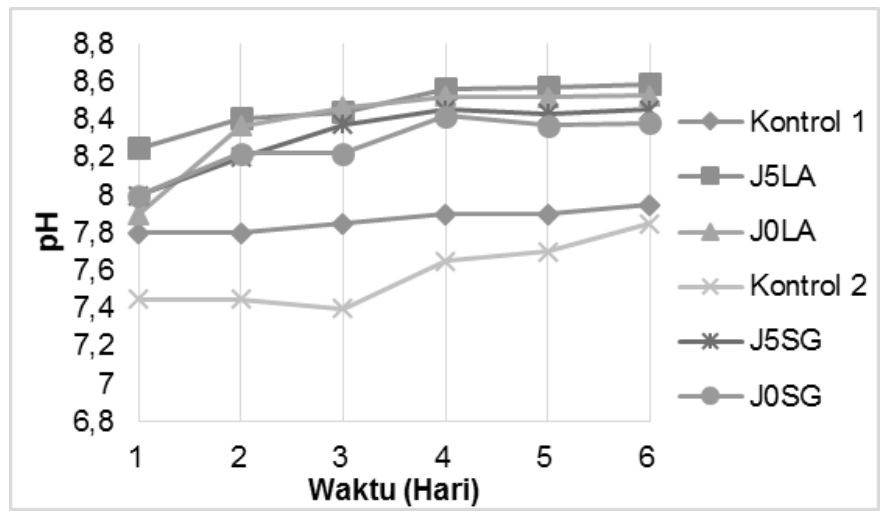

Gambar 4. pH Uji Penyisihan Logam Aluminium

Pada Gambar 4 rentang $\mathrm{pH}$ pada reaktor uji bioremediasi yakni 7,45 - 8,59. Rentang $\mathrm{pH}$ optimum A. niger adalah 2-8 [20]. Pengukuran $\mathrm{pH}$ hari ke-0 hingga ke-4 rata-rata masih dalam range $\mathrm{pH}$ optimum $A$. niger tetapi pada hari kelima $\mathrm{pH}$ di reaktor J5LA, J0LA, J5SG, dan J0SG cenderung berada di luar $\mathrm{pH}$ optimum. Hal ini dikarenakan terjadi penumpukan sel mati jamur sehingga $\mathrm{pH}$ cenderung menjadi basa.

\section{F. Analisis Kadar Air}

Selain parameter suhu dan $\mathrm{pH}$, terdapat parameter lainnya yakni kadar air. Pengukuran kadar air dengan menggunakan metode gravimetri sesuai dengan rumus (1) sehingga didapatkan kadar airnya dengan disajikan dengan grafik pada Gambar 5.

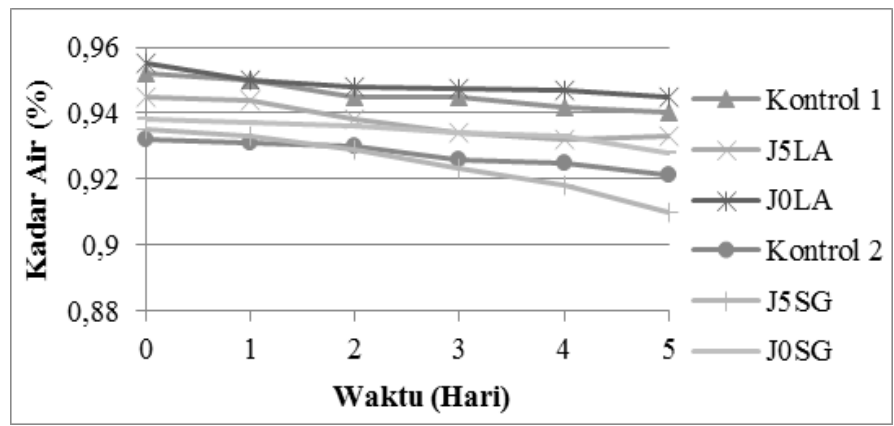

Gambar 5. Kadar Air Uji Penyisihan Logam Aluminium

Pengukuran kadar air dalam reaktor uji dengan penambahan jamur yang ditunjukkan pada Gambar 4.13. Rentang nilai kadar air yakni 93-95\%. Hal ini sesuai dengan kadar air optimal untuk pertumbuhan bakteri $A$. niger dengan rentang $90-100 \%$ [20]. Sehingga kadar air dalam reaktor uji masuk dalam rentang kadar air pertumbuhan optimal A. niger.

\section{G. Analisis Penyisihan Logam Aluminium}

Uji penyisihan logam aluminium diukur pada saat awal dan akhir penelitian. Pengukuran ini bertujuan mengetahui persentase penyisihan yang mampu dilakukan oleh jamur
Aspergillus niger dalam sampel yang mengandung logam aluminium. Hasil penyisihan aluminium dan konsentrasi aluminium pada saat awal dan akhir penelitian dapat dilihat pada Gambar 6.

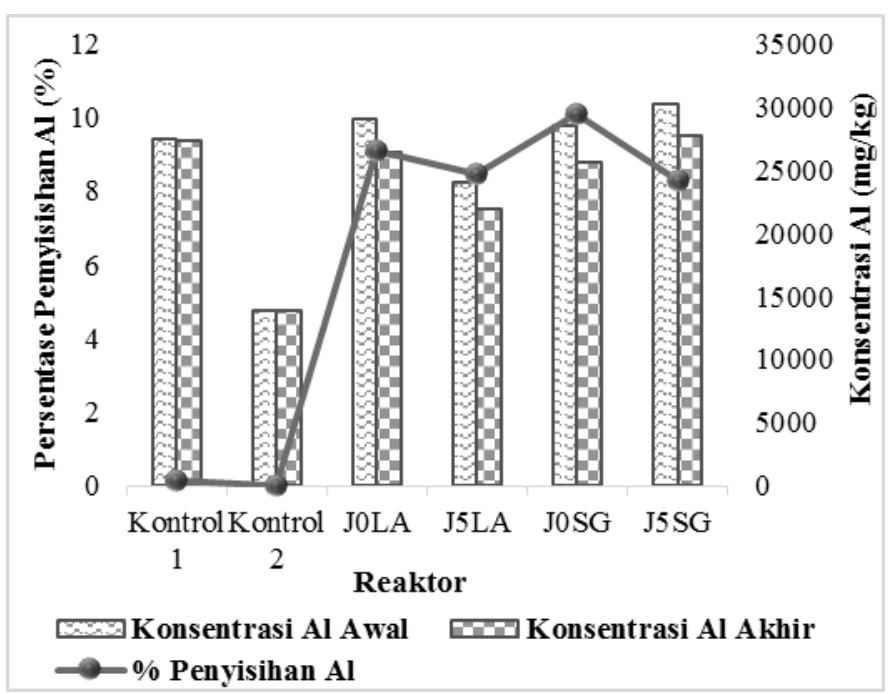

Gambar 6. Persentase Penyisihan Logam Aluminium oleh A. Niger

Pada Gambar 5 menunjukkan bahwa persentase penyisihan oleh A. niger yang terbesar pada reaktor J0SG yakni sebesar $10,11 \%$. Reaktor J0SG adalah penambahan $10 \% \mathrm{v} / \mathrm{v}$ pada sampel $97 \%$ lumpur alum: 3\% serbuk gergaji. Hal ini dikarenakan jumlah jamur yang ditambahkan berbanding lurus dengan tingginya persentase penyisihan yang dilakukan oleh $A$. niger. Kemudian pada perbandingan sampel, sampel $97 \%$ lumpur alum: 3\% serbuk gergaji memiliki persentase penyisihan lebih besar dari sampel 100\% lumpur alum, hal ini dikarenakan pada serbuk gergaji tidak terdapat jamur atau bakteri indigenous yang bersifat kompetitif dengan A. niger. Pada serbuk gergaji terdapat substrat lignoselulosa yang berfungsi sebagai senyawa untuk mendukung pertumbuhan fungi di dalam sampel [21]. Ligniselulosa adalah salah satu jenis selulosa atau senyawa organik yang menyusun dinding sel tanaman. Aspergillus niger memiliki enzim selulase yang akan memecah selulosa menjadi glukosa untuk proses metabolismenya [22]. Sehingga Aspergillus niger mampu memberikan penyisihan aluminium lebih banyak pada sampel $3 \%$ serbuk gergaji dan $97 \%$ lumpur alum dibandingkan dengan sampel $100 \%$ lumpur alum.

\section{KESIMPULAN/RINGKASAN}

Berdasarkan pembahasan diatas, maka kesimpulan dalam penelitian ini adalah karakteristik lumpur alum dari IPAM X yakni memiliki konsentrasi aluminium $250 \mathrm{mg} / \mathrm{L}$, pH 8,61 dengan suhu $31^{\circ} \mathrm{C}$, massa jenis $1240 \mathrm{~kg} / \mathrm{m}^{3}$, kadar air $98 \%$ serta angka porositasnya 0,0230 . Pada penambahan 5 dan $10 \%$ $(\mathrm{v} / \mathrm{v})$ Aspergillus niger didapatkan efisiensi penyisihan aluminium pada sampel $100 \%$ lumpur alum yakni masingmasing $8,45 \%$ dan $9,08 \%$ sedangkan pada sampel $97 \%$ lumpur alum dan 3\% serbuk gergaji yakni masing-masing $8,27 \%$ dan $10,11 \%$. Bioremediasi yang paling efektif untuk penyisihan 
aluminium yakni pada penambahan $10 \%$ (v/v) Aspergillus niger pada $97 \%$ lumpur alum dan $3 \%$ serbuk gergaji sebesar $10,11 \%$.

\section{UCAPAN TERIMA KASIH}

Penulis mengucapkan terima kasih kepada dosen pembimbing dan dosen penguji tugas akhir atas saran dan masukan terhadap penulisan jurnal.

\section{DAFTAR PUSTAKA}

[1] D.A. Georgantas dan H.P. Grigoropoulou. 2005. Phosphorus Removal from Synthetic dan Municipal Wastewater using Spent Alum Sludge. Water Science and Technology, 52, 525-532.

[2] H. Nurmansah dan N. Karnaningroem. 2012 Pemanfaatan Lumpur Endapan untuk Menurunkan Kekeruhan dengan Sistem Batch. Jurusan Teknik Lingkungan Institut Teknologi Sepuluh Nopember.

[3] K.B. Dassanayake, G.H. Jayasinghe, dan C. Hetherington. 2015. A Review on Alum Sludge Reuse with Special Reference to Agricultural Applications and Future Challenges. Waste Management Journal, 38, 321-335.

[4] S. Az-Zahra, Rahmawati, dan E. Wardhani. 2014. Karakteristik Kualitas Air Baku dan Lumpur sebagai Dasar Perencanaan Instalasi Pengolahan Lumpur IPA Badak Singa PDAM Tirtawening Kota Bandung. Jurnal Rekayasa Lingkungan, 2 (2), 1-10.

[5] T.E. Lewis. 1990. Environmental Chemistry and Toxicity of Aluminium. Michigan: Lewis Publisher.

[6] A.C. Guyton dan J.E. Hall. 1996. Textbook of Medical Physiology. Philadelpia: W.B. Saunders Company.

[7] H. Fitri. 2010. Dampak Pembuangan Lumpur Perusahaan Daerah Air Minum Kota Pontianak Terhadap Kualitas Air Sungai Kapuas. Jurusan Teknik Lingkungan Universitas Tanjungpura.

[8] UNECE. 1994. Standard Statistical Classification of Surface Freshwater Quality for Maintenance of Aquatic Life. In: Readings in International Environment Statistic. United Nations Economic Commission for Europe, United Nations, New York and Geneva.

[9] J.R. Evelyne dan V. Ravisankar. 2014. Bioremediation of Chromium Contamination- A Review. Journal of Research in Earth \& Environmental Science, 1(6), 20-26.

[10] M. Udiharto. 1992. Aktivitas Mikroba dalam Degradasi Crude Oil. Diskusi Ilmiah VII. Lemigas Research. Jakarta.

[11] A. Kumar, B.S. Bisht, dan V.D. Joshi. 2010. Biosorption of Heavy Metals by Four Microbial Species, Bacillus spp., Pseudomonas spp., Staphylococcus spp., and Aspergillus niger. Journal of Biology Environmental Science, 4 (12), 97-108.

[12] D. Santhiya dan Y. Ting. 2006. Use of Adapted Aspergillus niger in Bioleaching of Spent Refinery Processing Catalyst. Journal of Biotechnology, 121 (1), 62-74.

[13] N. Pradhan, B. Das, C.S. Gahan, R.N. Kar, dan R.B. Sukla. 2006. Beneficiation of Iron Ore Slime using Aspergillus niger and Bacillus circulans. Journal of Bioresource Technology, 97 (1), 1876-1879.

[14] T. Retno dan N. Mulyana. 2013. Bioremediasi Lahan Tercemar Limbah Lumpur Minyak Menggunakan Campuran Bulking Agents yang Diperkaya Konsorsia Mikroba Berbasis Kompos Iradiasi. Jurnal Ilmiah Aplikasi Isotop dan Radiasi, 9 (2), 139-150.

[15] A.R. Putri, S.Z. Amraini, dan Bahruddin. 2014. Pengaruh Kadar Serbuk Gergaji Dalam Proses Bioremediasi Tanah Tercemar Minyak. Jurnal Online Mahasiswa Fakultas Teknik Universitas Riau, 1 (1), 1-6.

[16] A. Hadi. 2005. Prinsip Pengelolaan Pengambilan Sampel Lingkungan. Jakarta: PT. Gramedia Pustaka Utama.

[17] N. Noriko, D. Elfidasari, A.T. Perdana, N. Wulandari, dan W. Wijayanti. 2012. Analisis Penggunaan dan Syarat Mutu Minyak Goreng Makanan di Food Court UAI. Jurnal Al-Azhar Seri Sains dan Teknologi, 1(3), 147-154.

[18] L. Antika, E. Julianty, Miroah, A. Nurul, dan F. Hapsari. 2012. Pengukuran (Kalibrasi) Volume dan Massa Jenis Aluminium. Spektra: Jurnal Fisika dan Aplikasinya, 13(1), 24-28.
[19] J. Meletiadis, J.F.G.M. Meis, J.W. Mouton, dan P.W. Verweij. 2001. Analysis of Growth Characteristic of Filamentous Fungi in Different Nutrien Media. Journal of Clinical Microbiology, 39(2), 478-484.

[20] K. Fiedler, E. Schutz, dan S. Geh. 2001. Detection of Microbial Volatile Organic Compounds (MVOCs) Produce by Moulds on Various Materials. International Journal of Hygene Environmental Health, 204, 111-121.

[21] E. Lang. 1995. Interaction of white rot fungi and microorganisms leading to biodegradation of soil pollutants. Fifth International Conf. Contaminated Soils, 9(5), 1277-1278.

[22] I.W. Arnata. 2009. Teknologi Bioproses Pembuatan Bioetanol dari Ubi Kayu Menggunakan Trichoderma viride, Aspergillus niger, dan Saccharomyces cerevisiae. Thesis Master, IPB, Bogor. 